\title{
Deterministic pore pressure estimation for shaly sand formations through conventional petrophysical data and integrated 1D geomechanical approach.
}

Renzo Francia ${ }^{1}$, Fernando Moraes ${ }^{1,2},{ }^{1}$ Grupo de Inferência de Reservatório da Universidade Estadual do Norte Fluminense, Macaé, Brazil; ' Instituto Nacional de Ciência e Tecnologia de Geofísica do Petróleo (INCT-GP/CNPq), Salvador, Brazil

Copyright 2019, SBGf - Sociedade Brasileira de Geofísica

This paper was prepared for presentation during the $16^{\text {th }}$ International Congress of the Brazilian Geophysical Society held in Rio de Janeiro, Brazil, 19-22 August 2019.

Contents of this paper were reviewed by the Technical Committee of the $16^{\text {th }}$ International Congress of the Brazilian Geophysical Society and do not necessarily represent any position of the SBGf, its officers or members. Electronic reproduction or storage of any part of this paper for commercial purposes without the written consent of the Brazilian Geophysical Society is prohibited.

\begin{abstract}
Pore pressure estimation in sedimentary basins has been made exclusively through the compressional velocity data since the 60`s, using the normal compaction trend and lithostatic pressure profile derived from wireline logs. Considering that seismic velocity is highly dependent on petrophysical parameters such as porosity and lithology, pore pressures estimates are commonly associated with a high degree of uncertainty due to simplistic assumptions that neglect those dependencies. To improve that, we propose an empirical velocity model for pore pressure prediction in sands or shaly-sands, which accounts for porosity and shale volume variations. Our formulation is an extended form of Bowers and Doyen formulae, used to link pore pressure to compressional velocity, effective pressure, porosity, shale volume and fluid volumes. To check our approach, we make comparative estimations, using Eaton method in the context of a geomechanics and pore pressure prediction study, involving overpressured reservoir sands. The results show good agreement between both methods.
\end{abstract}

\section{Introduction}

Knowledge of formation pore pressure is a key requirement for optimal field development and well design decisions, with an impact on safely during drilling operations, especially for deep exploration and production wells. Pore pressure estimation has a great value for the oil industry, since helps drilling and oil recovery optimization. Estimates are performed using seismic velocity and sonic log data, following a workflow consisting of two main steps: 1) obtaining the compressional velocities $\left(V_{P}\right)$ on the formation, which is done through adequate seismic and processing and/or sonic acquisition (Sayers et al., 2002; Dutta, 2002; Kan and Swan, 2001; Malinverno 2004); 2) a posterior transformation of these velocities into pore pressure with quality control checks to adjust ideal input variables.

The pore pressure transformation is done through semiempirical relations based in effective stress methods developed for non-reservoir rocks (shaly formations), as presented by Hottman and Johnson (1965), Eaton (1976) and Bowers (1995). Very often, such relations have been indiscriminately applied for all formation types including reservoir sands. It was not until a decade later that authors, led by Carcione et al. (2002), Dvorkin et al (2002), Sayers et al. (2003) and Doyen et al. (2004), proposed new models for pore pressure estimation in reservoir rocks, what represents an advance for the pore pressure studies.

Despite this more recent advance, the traditional methods are still been widely used for shaly rocks and reservoir intervals. The traditional methods are based on a simple relation between $V_{P}$ and pore pressure (actually, $V_{P}$ vs. effective pressure, for a given lithostatic pressure), which is locally calibrated to yield proper pore pressure estimates in the target intervals. As the elastic properties in sand-shale rocks may vary significantly with porosity and lithology, as has been widely demonstrated in the studies, such as those by Castagna et al. (1985), Han et al. (1986) and Eberhart-Phillips et al. (1989), the estimated pore pressure becomes subjected to this potential source of error. Therefore, more complete approach to pore pressure estimation involves testing new models with increased number of petrophysical parameters and perhaps bringing other seismic attributes to reduce the uncertainty.

Here we follow on this path by proposing and testing an extended form of Bowers (1995) and Doyen et al. (2004) formulae that gives pore pressure as a function of compressional velocity, overburden stress, porosity, clay and fluids volumes.

\section{Conventional Deterministic Approaches for Pore Pressure Prediction}

Traditionally, pore pressure calculation formulas have been proposed to be used on a set of wireline logs and downhole measurements. Virtually all methods rely on the principle of compaction disequilibrium and require the definition of a normal compaction trend profile, which represents the gradual decrease in porosity with increasing lithostatic pressure under normal depositional conditions. Deviations from the normal compaction trend are indications of abnormal pore pressure as result of some mechanism of overpressure generation. Thus, pore pressure estimation methods are based on the observation that pore pressure influences compactiondependent shale properties such as porosity, density, sonic velocity, and resistivity. This observation became the foundation of two different approaches to pore pressure prediction, which are the direct method (Hottman and Johnson, 1965; Pennebaker, 1968), and 
the effective stress method, based on Terzaghi's principle (Foster and Whalen, 1966; Eaton, 1975; Lane and Macpherson, 1976; Bowers, 1999). Bowers (1999) refers to any type of geophysical data that is sensitive to pore pressure as a pore pressure indicator.

Currently, effective stress methods dominate porepressure prediction works. Terzaghi's effective stress principle (Terzaghi, 1943) states that compaction of geologic materials is controlled by the difference between the total confining pressure and the pore fluid pressure. Lane and Macpherson (1976) proposed a separation of these methods into two classes that are respectively based on the vertical and horizontal effective stresses (see Bowers, 1999). In these methods, compressional velocity plays a central role, considering it is directly affected by effective stresses. Therefore continuous efforts have been made to obtain reliable compressional velocity data and/or estimates, in addition to the development of comprehensive modeling formulations.

One problem that arises in pore pressure quantification with effective stress methods is that it works more accurately in shale formations, due to its compaction behavior. In sand or shaly sand formations the application of effective stress methods is more problematic, considering that compaction is significantly smaller and compressional velocity is strongly affected by porosity, shale volume and saturation.

Another problem relates to availability of pore pressure measurements, which are made using flow dependent tools, making those measurements possible only in intervals with significant permeability values. Pore pressure prediction in sandstone before drilling (predrill stage), can be performed from direct pressure measurements from sand layers in neighboring wells.

To reconciliate the direct pore pressure measurements in sandstones with the effective stress approach formulated for shales, it is essential to understand pore pressure behavior in shale and other tight formations with ultra-low permeability. This requires another approach, commonly used during 1D mechanical earth model (MEM) characterization (Oughton et al., 2018; Sayers et al., 2006; Plumb et al., 2000). For example, if an elevated pore pressure is the result of undercompaction, due to fluid trapping during burial, this is refereed by some authors as disequilibrium compaction phenomenon. In this case, the sediment porosities will be anomalously high and the velocities anomalously low (Zoback, 2010). Abnormal sand-body pressure is often observed in equilibrium with surrounding undercompacted shale layers.

\section{Proposed formulation}

Following Sayers et al. (2003) and Doyen et al. (2004), we start from an empirical expression of $\mathrm{P}$-wave velocity as a function of $V_{P}$, pore pressure $P_{P}$, overburden pressure $P_{o}$, porosity $\emptyset$, shale volume $C$, and oil volume $V_{\text {oil }}$.

$V_{P}=a_{1}-a_{2} \varnothing-a_{3} C-a_{4} V_{\text {oil }}+a_{5}\left(P_{o}-P_{P}\right)^{a_{6}}$,

where $\boldsymbol{a}_{\boldsymbol{i}}, \boldsymbol{i}=\mathbf{1}, \ldots, \mathbf{5}$ are the model coefficients, whose values are determined by calibration using well-log data.
In the above equation, the velocity dependence on effective pressure, given by the $\boldsymbol{P}_{\boldsymbol{o}}-\boldsymbol{P}_{\boldsymbol{P}}$, is equivalent to that proposed by Bowers (1995), with the terms $\boldsymbol{a}_{\mathbf{1}}-$ $\boldsymbol{a}_{2} \emptyset-\boldsymbol{a}_{3} \boldsymbol{C}-\boldsymbol{a}_{4} \boldsymbol{V}_{\text {oil }}$ being compactly represented by a constant value called the zero-stress mudline velocity $\boldsymbol{V}_{\boldsymbol{o}}$, in his model. By introducing these terms in our model, we can account for variations in porosity, lithology and volume of oil. These developments are also related to models presented by Han et al. (1986) and EberhartPhillips et al. (1989).

Taking Equation (1), we can rewrite it, in a straight forward way, to obtain an expression for the pore pressure, as given by

$P_{P}=P_{o}-\left[\frac{1}{a_{5}}\left(V_{p}-a_{1}+a_{2} \emptyset+a_{3} C+a_{4} V_{o i l}\right)\right]^{\frac{1}{a_{6}}}$.

Equation (2) may be applied point-by-point in a 3-D MEM or 1-D MEM, assuming that a velocity is available from seismic inversion or interpolated using data from nearby wells, including sonic compressional logs, and porosity, shale volume and fluid volumes. In practice, the velocity to pore pressure transform must be calibrated for each formation and fluid type.

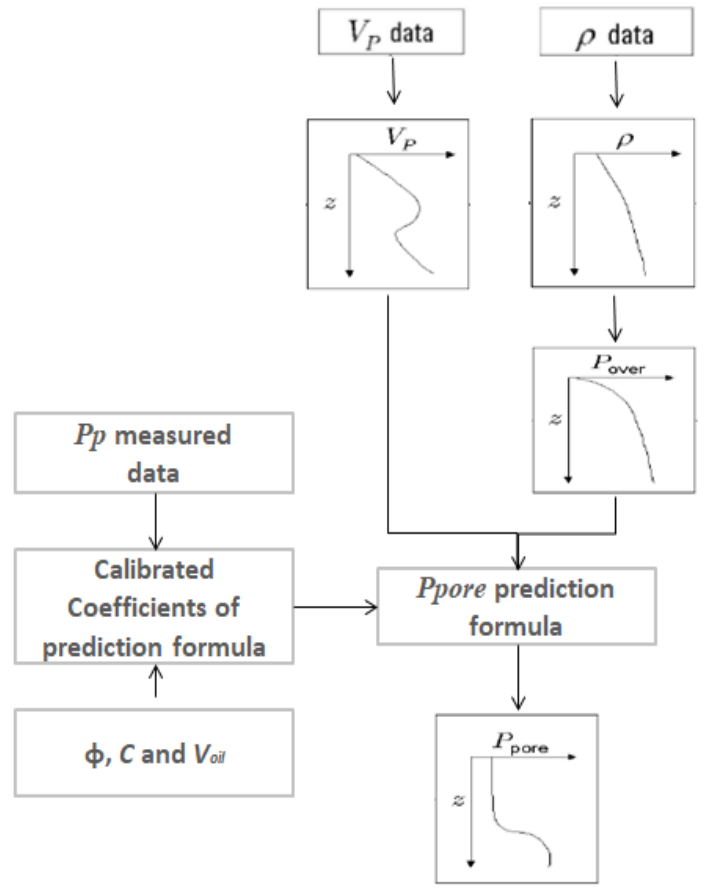

Figure 1: Basic workflow for predicting pore pressure using Equation (1), and input using well-log or seismic derived velocity and density.

The overburden pressure, $\boldsymbol{P}_{\boldsymbol{o}}$ required in the calculation of $\boldsymbol{P}_{\boldsymbol{P}}$ can be obtained integration of the density function, given by

$$
P_{o}(z)=g \int_{0}^{z} \rho(z) d z
$$

where $z$ is the vertical depth, $g$ is the acceleration of gravity and $\rho$ is the bulk density. In practice, the integral 
is calculated from a density cube either from elastic inversion or well log data from the surface to depth $z$, as in 1-D MEM building.

The velocity and overburden pressure (obtained by integrating the density) as well as porosity, shale fraction, volume of fluids and coefficients of calibration are then input to a formula that computes a predicted porepressure profile (Fig.1), together with calibrated model coefficients and petrophysical parameters derived from well data. The proposed can be described, in more detail, by the following steps:

1. Construct the best velocity $V_{p}(z)$, and density $\rho(z)$ depth profiles.

2. Use the density $\rho(z)$ to estimate the total vertical stress (TVS) or overburden pressure $\boldsymbol{P}_{\boldsymbol{o}}$ (Eq.3).

3. Petrophysical interpretation - compute shale volumes, porosity and saturation (i.e., mineral and fluid solver analysis) using wireline data, and perform lithologic interpretation discriminating the shales and sand/shaly sands intervals.

4. Calibrate model coefficients - use the results of previous step, together with pore pressure data, to obtain coefficients $\boldsymbol{a}_{\boldsymbol{i}}$, as in equation (2), using a preferred regression algorithm (Fig. 2).

5. Compute the predicted pore pressure $\boldsymbol{P}_{\boldsymbol{P}}$ for sand and shaly sand sections including petrophysical data using equation (2) with inputs from the previous steps, contrasting the predicted pore pressure with the pore pressure data and mud weight for quality control.

Considering the semi-empirical nature of the proposed formulation, it is always important to check against competing approaches, such as represented by the Eaton's method (Eaton, 1975).

\section{Case Study}

Our survey was done in a consolidated paleocene shaly sand oil reservoir. The interval analyzed shows abnormal pressures (abnormal means above hydrostatic local pressure). The data used in this study consists of clay volume, porosity, water saturation (petrophysical processed curves), compressional slowness, density logs, direct measures of pore pressure and mud weight.

The calibration process of our proposed equation defined in previous steps, was done by adjusting the effective pressure (PP_ef in bars units) and $\boldsymbol{V}_{\boldsymbol{p}}-\boldsymbol{V}_{\boldsymbol{o}}$ (V_DIFF in $\mathrm{km} / \mathrm{s}$ units), following Bowers conventional power law curve fitting method (Sayers, 2003) using available well data, as observed in Fig.2.

$\boldsymbol{V}_{\boldsymbol{o}}$ is the mudline velocity, as defined previously, and represent the term $\boldsymbol{a}_{\mathbf{1}}-\boldsymbol{a}_{\mathbf{2}} \emptyset-\boldsymbol{a}_{\mathbf{3}} \boldsymbol{C}-\boldsymbol{a}_{\mathbf{4}} \boldsymbol{V}_{\text {oil }}$ in equation (2). These four coefficients were treated like weights and additional calibration factors in this study considering that coefficients $\boldsymbol{a}_{\mathbf{5}}$ and $\boldsymbol{a}_{\mathbf{6}}$ was obtained through the power law relation. In Fig. 3 we have petrophysical curves of clay volume (VCL), effective porosity (PHIE) and water volume of undisturbed zone (VUWA) displayed in the second track. Third track shows the compressional slowness
(DTCO) and their respective normal slowness trend used used in the Eaton pore pressure estimation method.

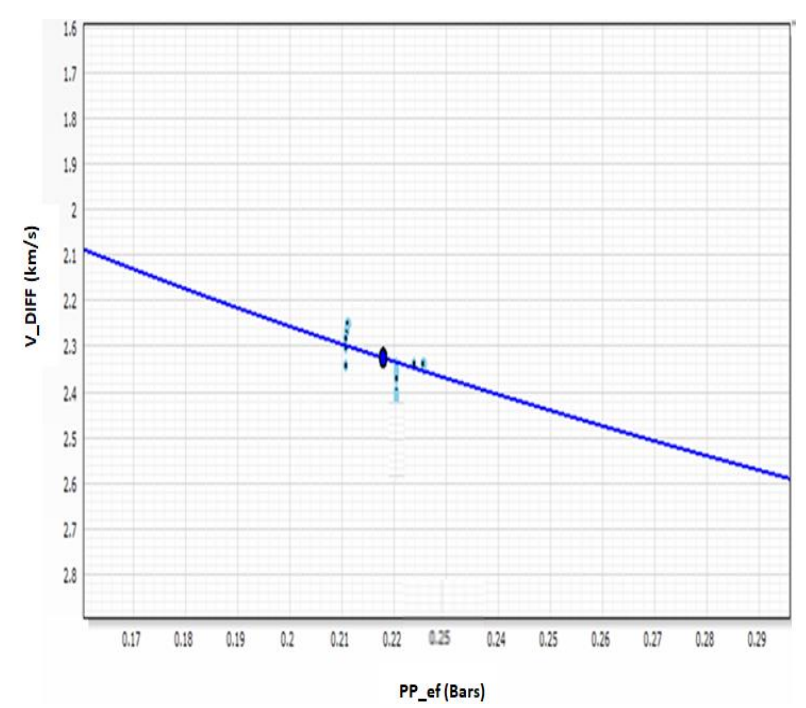

Figure 2: Calibration coefficient process through power law fitting using overburden with subtracting direct pore pressure measures (PP_ef) vs. $\boldsymbol{V}_{\boldsymbol{p}}-\boldsymbol{V}_{\boldsymbol{o}}$ (V_DIFF).

Fourth track shows hydrostatic pore pressure (PPMW_NORM), Eaton pore pressure (PPMW_EATON_S), our proposed pore pressure approach (PPMW (RFT) and mud weight (MW). All pressure curves are in pounds pour gallon units (ppg).

Both methods used for pore pressure estimation show good agreement with direct pore pressure measurements. An important difference observed in our proposed method is the distribution of pressures along the shaly sand section intervals showing a more realistic behavior, taking into account the variations in lithology, porosity and fluid effects within the overpressured interval, in contrast with Eaton's formulation. Common processing practices following MEM 1D approaches, like Eaton method, use linear interpolation and constant gradient for pore pressure estimation in sand/shaly sand sections, using direct pore pressure measurements for adjusting and calibration, giving uncertainties in the real distribution of pore pressures.

\section{Conclusions and recommendations}

It is generally recognized that pore pressure predicted by Eaton's method is not exact, even if applicable. The necessary inputs are not accurately known (Malinverno, 2004). It would be desirable to have a methodology that predicts pore pressure by integrating all relevant petrophysical data available.

Our proposed method to estimate pore pressure integrates compressional-wave velocity, density (overburden), porosity, shale volume and fluid volumes (Eq,2), as an extension of a widely used empirical formula relating velocity with effective stress called Bowers method (1995). Our extended formulation follow the same 
lines of the extension proposed by Doyen et al. (2004), except for an extra term that is saturation dependent.

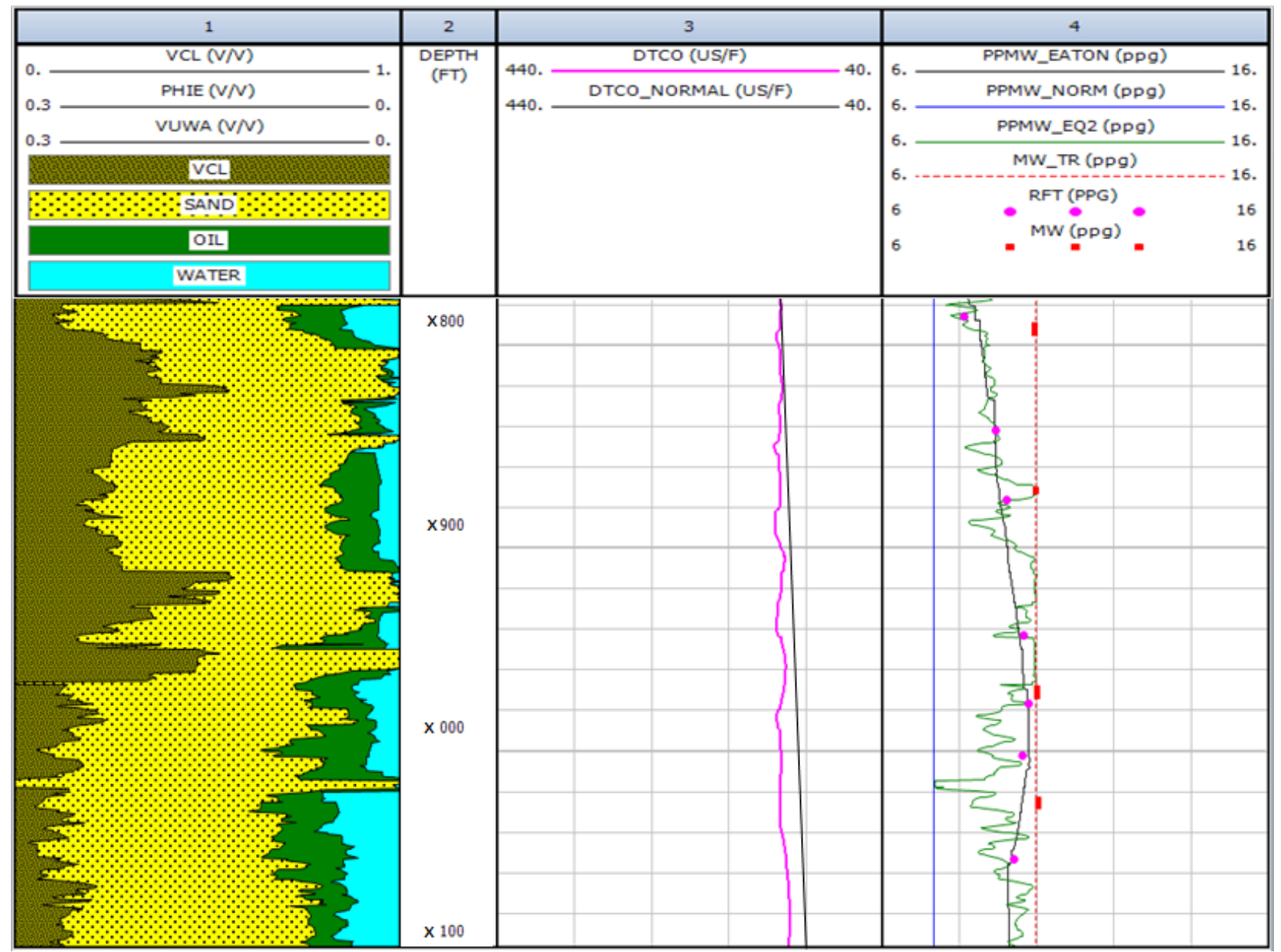

Figure 3: Final pore pressure composite consisting of four tracks, arranged as follows: (1) shading zones for VCL - SAND lithology and WATER - OIL fluids, and interpreted petrophysical data given by PHIE (effective porosity curve), VCL (clay volume) and VUWA (volume of water in undisturbed zone); (2) Relative depths in the second track; (3) Compressional slowness (DTCO) and normal trend (DTCO_NORMAL); (4) Hydrostatic pore pressure (PPMW_NORM), Eaton pore pressure (PPMW_EATON), our proposed pore pressure approach (PPMW_EQ2), direct pore pressure measures (RFT) and mud weight $(\overline{M W})$ in the fourth track. All pressure curves are in pounds pour gallon units (ppg).

We also used Eaton's method to predict pore pressure, in order to compare results with our proposed approach.

Both methods used for pore pressure estimation in these consolidated paleocene shaly sand oil reservoir case study show good agreement with direct pore pressure measurements and mud weight data (not kick's reported during drilling in these well). It is important to consider, however, that abnormal pressure observed in this field are linked with disequilibrium compaction overpressure as the dominant mechanism (loading mechanical mechanism dominant).

An important difference observed in our proposed method is the distribution of pressures along the shaly sand section interval showing a more realistic behavior in the overpressured interval As additional and future discussions, these local effects and behaviors of pore pressure must be studied taking into account heterogeneity of lithological and petrophysical properties that could result in changes of pore pressure distribution as observed in these case.

A wayforward of this analysis will be also to include a nonlinear optimization method for the calibration process as well as include other advance approach for uncertainty quantification of the inputs defined in these method (eg. stochastic Bayesian methods).

Following that seismic-based pore pressure calculations are best done with the help of a 3-D Mechanical Earth Model (MEM), as illustrated by Plumb et al. (2000), and predrill pore pressure predictions are often obtained from seismic velocities, using an empirical velocity to pore pressure transform, these approach could be applied and coupled for these kind of seismic for geomechanics 
surveys in order to reduce fluid uncertainties during the pore pressure transformation.

\section{Acknowledgments}

The authors would like to thank PETROBRAS for the financial support trough a research grant (TC 5850.0108361.18.9) and the PFRH-PB 226 Graduate Program in Applied Geophysics. We also thank the Conselho Nacional de Desenvolvimento Científico e Tecnológico (CNPq) for the financial support of the INCTGP and Coordenação de Aperfeiçoamento de Pessoal de Nível Superior (CAPES) for the institutional and financial support of the Graduate Program in Exploration and Reservoir Engineering.

\section{References}

BOWERS, G. L., 1995, Pore Pressure Estimation From Velocity Data: Accounting for Overpressure Mechanisms Besides Undercompaction. SPE Paper 27488.

BOWERS, G.L., 1999, State of the Art in Pore Pressure Estimation: DEA-119 Report No. 1.

CASTAGNA, J. P., BATZLE, M. L. \& EASTWOOD R. L., 1985, Relationship between compressional wave and shear wave velocities in clastic silicate rocks: Geophysics, V. $50,571-581$.

CARCIONE, J. M., HELLE, H. B., PHAM, N. H. \& TOVERUD, T., 2003, Pore pressure estimation in reservoir rocks from seismic reflection data. Geophysics, Volume 68, Issue 5, pp. 1569-1579.

DOYEN, P. M., MALINVERNO, A., PRIOUL, R., HOOYMAN, P., NOETH, S., BOER, L. PSAILA, D., SAYERS, C. M., SMIT, T. J. H., EDEM, C. \& WERVELMAN, R., 2004, Seismic pore pressure prediction with uncertainty using a probabilistic mechanical earth model. Anais do Encontro de sísmica 4D no Rio de Janeiro.

DUTTA, N. C., 2002, Geopressure Prediction Using Seismic Data: Current Status and the Road Ahead. Geophysics 67.

EATON, B. A., 1975, The equation for geopressure prediction from well logs. Presented at 50th Annual Fall Meeting of the Society of Petroleum Engineers of AIME, 5544.

EBERHART-PHILLIPS D., HAN D. \& ZOBACK M., 1989, Empirical relationships among seismic velocity, effective pressure, porosity, and clay content in sandstone. Geophysics vol. 54 nำ1, P82 - 89 .

FOSTER, J. B., \& WHALEN, J. E., 1966, Estimation of formation pressures from electrical surveys Offshore Louisiana: Journal of Petroleum Technology.

HAN D., NUR A. \& MORGAN D., 1986, Effects of Porosity and Clay Content on Wave Velocities in Sandstones. Geophysics, vol 51.

HOLZBERG, B. B. 2005. Probabilistic Pore Pressure Prediction in Reservoir Rocks Through Compressional and Shear Velocities. Ph.D. Dissertation, Catholic University of Rio de Janeiro, PUC-Rio (in Portuguese).
HOTTMANN, C. E. \& JOHNSON, R. K. 1965. Estimation of formation pressures from log-derived shale properties: Journal of Petroleum Technology, 17, 717-722, doi: 10.2118/1110-PA.

KAN, T. K. \& SWAN, H. W., 2001, Geopressure prediction from automatically-derived seismic velocities: Geophysics, 66, 1937-1946, doi: 10 .1190/1.1487135.

LANE, R. A., \& MACPHERSON, L. A., 1976, A Review of geopressure evaluation from well logs - Louisiana Gulf Coast, Journal of Petroleum Technology. .

MALINVERNO, A. \& BRIGGS, V. A., 2004, Expanded uncertainty quantification in inverse problems: Hierarchical Bayes and empirical Bayes. Geophysics 69.

MALINVERNO, A., SAYERS, C. M., WOODWARD, M. J. \& BARTMAN, R. C., 2004, Integrating diverse measurements to predict pore pressure with uncertainties while drilling: SPE Annual Technical Conference and Exhibition, SPE, Extended Abstracts, doi: 10.2118/90001MS.

MAVKO, G., MUKERJI, T. \& DVORKIN, J., 1998, The Rock Physics Handbook: Tools for Seismic Analysis in Porous Media. Cambridge University Press, United Kingdom.

OUGHTON, R. H., WOOFF, D. A., HOBBS, R. W., SWARBRICK, R. E. \& O'CONNOR, S. A., 2018, A sequential dynamic Bayesian network for pore pressure estimation with uncertainty quantification, Geophysics, 83 (2). D27-D39.

SAYERS, C.M., SMIT, T.J.H., VAN EDEN C., WERVELMAN, R., BACHMANN, B., FITTS, T., BINGHAM, J., MCLACHLAN, K., HOOYMAN, P., NOETH, S. \& MANDHIRI, D., 2003, Use of reflection tomography to predict pore pressure in overpressured reservoir sands, submitted for presentation at the SEG 2003 annual meeting.

SAYERS C. M., WOODWARD, M. J. \& BARTMAN R. C., 2002, Seismic pore-pressure prediction using reflection tomography and 4-C seismic data: The leading Edge, 188.

PENNEBAKER, E. S., 1968, An Engineering Interpretation of Seismic Data: SPE 2165.

PLUMB, R. A., EDWARDS, S., PIDCOCK, G. \& LEE, D., 2000, The Mechanical Earth Model Concept and its Application to High Risk Well Construction Projects: SPE 59128.

TERZAGHI, K., 1973, Theoretical Soil Mechanics: New York, John Wiley \& Sons, Inc.

ZOBACK, MARK D., 2010, Reservoir Geomechanics (Pbk. ed.). Cambridge: Cambridge University Press. ISBN 978-0521146197. 